\title{
Screening for sulphonylureas in the investigation of hypoglycaemia
}

\author{
P Y P Kwong MSc MRCPath J D Teale BSc PhD
}

\section{SUMMARY}

The most important cause of hypoglycaemia in the presence of high insulin and C-peptide concentrations is insulinoma. However, a similar picture arises from use of sulphonylureas, which is sometimes covert. All specimens received in two years by a supraregional assay service laboratory from adults with low glucose and inappropriately high insulin and C-peptide concentrations were tested for sulphonylureas by a radioimmunoassay that employed antibodies to glibenclamide. In sulphonylurea-positive cases a questionnaire was sent to the consultant responsible for the patient, to elicit further information.

Samples from 93 adult patients met the criteria, and $34(37 \%)$ of these gave a positive result on screening for sulphonylureas. The consultants provided further information on 31 of the 34 , and in 20 the presence of a sulphonylurea was unexpected. In 10 the features were such as to raise the possibility of factitious drug ingestion.

A simple screening technique applied to specimens from patients with hyperinsulinaemic hypoglycaemia indicated that, in a substantial proportion of cases, the patient was taking a sulphonylurea.

\section{INTRODUCTION}

Hypoglycaemia is a well-known adverse effect of sulphonylureas, but little is known about its true incidence ${ }^{1}$. Most of the reported studies were done on non-insulin-dependent diabetic patients taking sulphonylureas ${ }^{2,3}$. There are three main reasons why the incidence of sulphonylurea-induced hypoglycaemia is not known. First, no screening method for sulphonylureas has been available for use in patients with inappropriately high serum insulin and C-peptide concentrations, for which the two other important causes are insulinoma and autoimmune insulin syndrome ${ }^{4}$. Secondly, insulinomas are often small tumours and the lack of sensitivity and specificity in current imaging techniques makes them difficult to diagnose and locate ${ }^{5}$; a distal partial pancreatectomy is sometimes performed if the tumour cannot be found at operation ${ }^{6}$. Thirdly, the rarity of inappropriately raised serum insulin and $\mathrm{C}$-peptide in the presence of hypoglycaemia makes the role of sulphonylureas difficult to assess ${ }^{7}$.

We developed a direct radioimmunoassay for sulphonylureas and used it to screen for hypoglycaemia of this causation. The Supraregional Assay Service (SAS) Laboratory

SAS Hormone Laboratory, Clinical Laboratory, Royal Surrey County Hospital, Egerton Road, Guildford, Surrey GU2 7XX, UK

Correspondence to: Pandina Kwong, Department of Clinical Biochemistry, King George Hospital, Barley Lane, Goodmayes IG3 8YB, UK

E-mail: pandina.kwong@rbhc-tr.nthames.nhs.uk for Peptide Hormones in Guildford, UK, has taken a special interest in hypoglycaemia, and the large number of cases referred enabled us to reassess the contribution made by sulphonylurea-induced hypoglycaemia, following a preliminary report ${ }^{8}$.

\section{METHODS \\ Materials}

Glibenclamide, product code G0639, purchased from SigmaAldrich Co Ltd (UK), was used as standard material. Chlorpropamide, tolazamide and tolbutamide were purchased from Sigma-Aldrich Co Ltd, UK. The other drugs were gifts: glibornuride from Roche Products Ltd (Welwyn Garden City, UK); gliclazide from Servier Laboratories Ltd (Slough, UK); glimepiride from Hoechst Marion Roussel (Frankfurt, Germany), glipizide from Pfizer (Sandwich, UK), gliquidone from Sanofi Winthrop (Newcastle upon Tyne, UK), and sulphamethoxazole from GlaxoWellcome UK (Uxbridge, UK). The sheep anti-glibenclamide antibody was a gift from Dr S Hampton, University of Surrey (Guildford, UK). The Sac-Cel solid phase second antibody, donkey anti-sheep antibody coated cellulose suspension (DAS SacCel), product number A-SAC2, was purchased from IDS Ltd (UK). The tracer, $\left.{ }^{125} \mathrm{I}\right]$ glibenclamide, product number IM270, was purchased from Amersham, UK. All other chemicals and materials were purchased from standard commercial sources. 


\section{Assay protocol}

Assay buffer (phosphate buffer $50 \mathrm{mmol} / \mathrm{L}, \mathrm{pH} 7.4,0.1 \%$ sodium azide, $0.1 \%$ bovine serum albumin) was used to prepare working dilutions of tracer, antiserum and standards. Each vial of the tracer $\left[{ }^{125} \mathrm{I}\right]$ glibenclamide $(100 \mu \mathrm{Ci} / \mathrm{mL}$ with specific activity approximately $3.51 \mathrm{Ci} / \mathrm{mg}$ ) was diluted in $5 \mathrm{~mL}$ methanol to give a stock solution which was kept at $4^{\circ} \mathrm{C}$. The radioimmunoassay (RIA) was done in polystyrene tubes $(64 \times 11 \mathrm{~mm})$.

Duplicates of standard and sample tubes were set up by adding $100 \mu \mathrm{L} 8$-anilino-1-naphthalenesulphonic acid, ammonium salt $(4 \mathrm{mg} / \mathrm{mL}$ in distilled water), $200 \mu \mathrm{L}$ antiglibenclamide antiserum (1 in 10000 dilution) and $200 \mu \mathrm{L}$ tracer (1 in 20 dilution of stock methanol tracer to give $14 \mathrm{pg} / \mathrm{mL}$ ) to $20 \mu \mathrm{L}$ glibenclamide standard (over the range 0-128 $\mu \mathrm{g} / \mathrm{L}$ ), control, or unknown sample. The tubes were vortex mixed and incubated overnight at $4^{\circ} \mathrm{C} .200 \mu \mathrm{L}$ tracer was pipetted into two tubes and stoppered for total counts.

To all tubes, except for the total counts, was added $100 \mu \mathrm{L}$ DAS SacCel. All tubes were vortex mixed and were allowed to stand at room temperature for $30 \mathrm{~min}$. Distilled water $(1 \mathrm{~mL})$ was added to all tubes except for the total tubes. The tubes were centrifuged immediately at $3000 \mathrm{rpm}$ for $15 \mathrm{~min}$ at $4^{\circ} \mathrm{C}$.

After centrifugation, the supernatant from each tube was aspirated and the pellet counted for $1 \mathrm{~min}$ in a LKB Wallac 1260 multigamma counter. The radioactivity of the pellet was expressed as counts per minute. A standard curve of radioactivity was plotted against log sulphonylurea concentration. Sulphonylurea concentrations of the unknown samples were derived from the standard curve.

\section{Assay characteristics}

The sensitivity of the assay was assessed by use of replicate zero standards $(n=20)$ prepared in assay buffer. The mean count of the zero standard and the standard deviation were calculated and the sensitivity of the assay, defined as the sulphonylurea concentration equivalent to three times the intra-assay standard deviation at zero concentration, was calculated as $0.5 \mu \mathrm{g} / \mathrm{L}$.

The imprecision of the assay was assessed by the coefficients of variation derived from serum samples analysed in several assays. Three serum pools spiked with glibenclamide standard to different concentrations were analysed in twenty assays. The between-batch imprecision $(n=20)$ was $19.7 \%$ at $10.5 \mu \mathrm{g} / \mathrm{L}, 13.9 \%$ at $54.2 \mu \mathrm{g} / \mathrm{L}$ and $14.7 \%$ at $106.1 \mu \mathrm{g} / \mathrm{L}$.

The specificity of the method was assessed by measuring apparent response caused by other commonly used sulphonylureas and sulphonamides. Increasing concentrations of
Table 1 Cross-reactivity of drugs with radioimmunoassay for sulphonylureas

\begin{tabular}{lc}
\hline Drug & Cross-reactivity \\
\hline Glibenclamide & $100 \%$ \\
Glipizide & $132 \%$ \\
Gliquidone & $60 \%$ \\
Glimepiride & $12.3 \%$ \\
Tolazamide & $2.6 \%$ \\
Tolbutamide & $0.8 \%$ \\
Gliclazide & $0.5 \%$ \\
Chlorpropamide & $0.1 \%$ \\
Glibornuride & Nil up to $50 \mathrm{mg} / \mathrm{L}$ \\
Sulphamethoxazole & Nil up to $50 \mathrm{mg} / \mathrm{L}$ \\
\hline
\end{tabular}

glimepiride, tolazamide, gliclazide, glipizide and sulphamethoxazole were prepared from stock solutions of $1 \mathrm{mg} / \mathrm{mL}$ in methanol. The concentration of each compound required to induce a $50 \%$ decrease in tracer binding (displacement dose, $\mathrm{DD}_{50}$ ) was measured and its cross-reactivity was calculated by comparison with the $\mathrm{DD}_{50}$ for glibenclamide. The response to each compound is listed in Table 1.

\section{Referred cases}

Over two years all specimens from adults received by the Guildford SAS Hormone Laboratory with confirmed hypoglycaemia $(<3.0 \mathrm{mmol} / \mathrm{L})$ were analysed for insulin and Cpeptide. Insulin was measured by an established in-house double-antibody competitive RIA ${ }^{9}$; the antibodies crossreacted $100 \%$ with insulin and proinsulin. C-peptide was measured by a competitive RIA kit obtained from Guildhay Limited (Guildford, UK).

Screening for sulphonylurea was performed on all specimens with inappropriately raised (i.e. measurable) insulin and C-peptide concentrations. A positive result was registered for concentration $\geqslant 0.5 \mu \mathrm{g} / \mathrm{L}$. Proinsulin concentration was measured in all samples by an established in-house double-antibody competitive RIA ${ }^{10}$.

For the sulphonylurea-positive cases, a questionnaire asking for further details on case history, differential diagnosis at the time of investigation and final diagnosis was sent with ethical approval to the initiating laboratory or, if known, to the consultant looking after the patient at the time of investigation.

\section{RESULTS}

93 adult cases with inappropriately raised insulin and Cpeptide concentrations in the presence of confirmed hypoglycaemia were identified from requests referred to the 


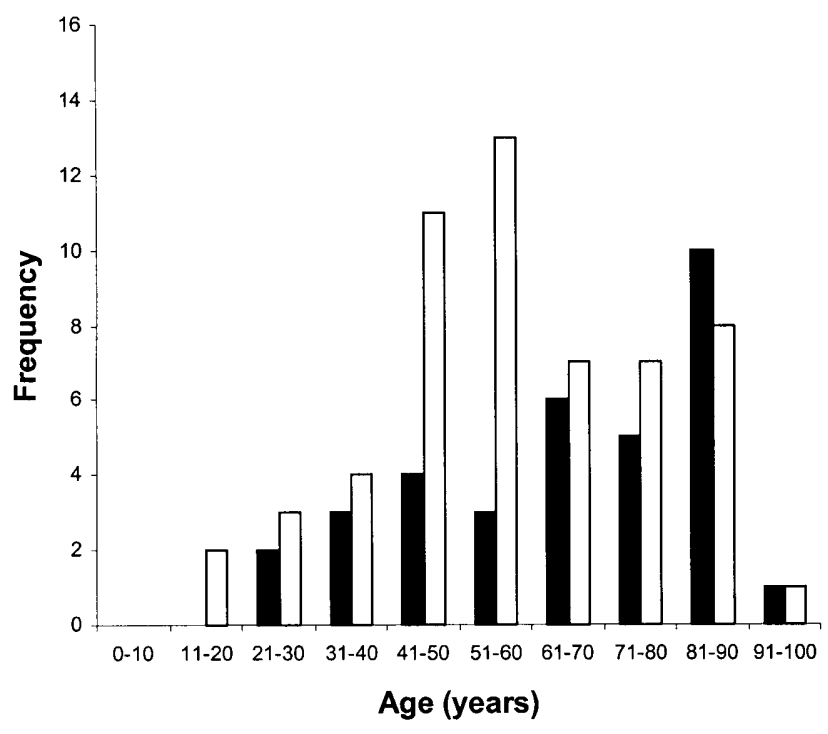

Figure 1 Age distribution of hyperinsulinaemic patients, classified as positive or negative for sulphonylureas. $\square$ Positive; $\square$ negative

laboratory. On screening for sulphonylureas, 34 (37\%) were found to be positive.

Figure 1 shows the ages of the patients with complete details who had hyperinsulinaemic hypoglycaemia, divided into positive or negative for sulphonylureas. The incidence of sulphonylurea-induced hypoglycaemia became higher with age, $32 \%$ of patients being over the age of 80 years (the median age of patients with sulphonylurea-negative hypoglycaemia was 55 years).

Completed questionnaires were returned by 31 (91\%) consultants, and 20 of these said that the role of a sulphonylurea had not been suspected.

12 of the 31 patients were known to have non-insulindependent diabetes (NIDDM). In 11 of these 12 the patient was hypoglycaemic when the blood sample was taken and it was established that, at that time, they were taking glibenclamide (5), gliclazide (3), tolbutamide (1) or glipizide
(1) on prescription; in one the therapy was unknown. Sulphonylurea assay results showed a wide range of concentrations $(10-371 \mu \mathrm{g} / \mathrm{L})$ with no apparent correlation with drug type.

Of the 19 patients who did not have diabetes 6 were elderly and 3 were mentally ill (details in Table 2). In 3 of the elderly patients the source and type of sulphonylurea was identified. In the other 3, who were in nursing homes, the probable explanation was drug dispensing error.

3 mentally ill patients were living in residential homes. 2 of these, from a single institution, were admitted to casualty with profound hypoglycaemia within a month of each other. One had taken glibenclamide tablets that belonged to another patient and was left in a permanent vegetative state after prolonged coma.

In the 10 remaining cases clinical evidence raised the possibility of factitious drug ingestion. The case histories are summarized in Table 3.

Proinsulin concentrations varied over a wide range in both sulphonylurea-positive (5-234 pmol/L) and negative $(<4-320 \mathrm{pmol} / \mathrm{L})$ groups. Proinsulin expressed as a percentage of total immunoreactive insulin ranged from $5 \%$ to $82 \%$ in the sulphonylurea-positive cases and from $<4 \%$ to $133 \%$ in the sulphonylurea-negative (undiagnosed) cases. These data compare with a percentage range of $2-128 \%$ in 40 cases of histologically confirmed insulinoma. In none of these were sulphonylureas detectable (unpublished).

\section{DISCUSSION}

The RIA reported here is sensitive and rapid, and can measure concentrations as low as $0.5 \mu \mathrm{g} / \mathrm{L}$ without extraction or other separative procedures. The small sample volume requirement enables a full work-up for the investigation of spontaneous hypoglycaemia to be done on a single specimen - an important consideration in paediatric and forensic cases. Although chlorpropamide, gliclazide and tolbutamide cross-react with the assay at a low level, these

Table 2 Data from elderly/mentally ill patients

\begin{tabular}{llllll}
\hline No. & $\begin{array}{l}\text { Age } \\
\text { (years) }\end{array}$ & Sex & $\begin{array}{l}\text { Glucose } \\
(\mathbf{m m o l} / \mathbf{L})\end{array}$ & $\begin{array}{l}\text { Sulphonylureas } \\
(\boldsymbol{\mu g} / \mathbf{L})\end{array}$ & Source of drug \\
\hline 1 & 85 & M & 1.0 & 60 & Wife's glibenclamide \\
2 & 88 & M & 0.7 & 13 & Wife's glibenclamide \\
3 & 78 & M & 1.1 & 109 & Wife's chlorpropamide \\
4 & 85 & F & 1.3 & 40 & Nursing home \\
5 & 85 & M & 1.4 & 19 & Nursing home \\
6 & 90 & F & 1.5 & 18 & Nursing home \\
7 & 36 & F & 0.1 & 54 & Mental home \\
8 & 45 & M & 1.3 & 235 & Mental home \\
9 & 47 & F & 0.7 & 44 & Mental home \\
\hline
\end{tabular}




\begin{tabular}{|c|c|c|c|c|c|c|}
\hline No. & $\begin{array}{l}\text { Age } \\
\text { (years) }\end{array}$ & Sex & $\begin{array}{l}\text { Glucose } \\
\text { (mmol/L) }\end{array}$ & $\begin{array}{l}\text { Sulphonylureas } \\
(\mu g / L)\end{array}$ & Suspected & Comments \\
\hline 1 & 53 & M & 1.3 & 155 & Yes & 'Accidently' taken wife's sulphonylureas \\
\hline 2 & 51 & $\mathrm{~F}$ & 1.8 & 42 & Yes & Admitted via casualty. Apparent self-poisoning \\
\hline 3 & 42 & M & 2.1 & 530 & Yes & $\begin{array}{l}\text { Farmer developed severe hypoglycaemia at home but not in } \\
\text { hospital. Diabetic relative in house. Denied drug-taking }\end{array}$ \\
\hline 4 & 54 & M & 2.1 & 73 & No & $\begin{array}{l}\text { Collapsed at work. History of weight loss, hunger and } \\
\text { blackouts. Denied taking drugs or alcohol }\end{array}$ \\
\hline 5 & 31 & $\mathrm{~F}$ & 1.9 & 8 & No & $\begin{array}{l}\text { 'Rare blood disorder' diagnosed in Belgium, ?ME. Raised } \\
\text { ESR. Denied taking sulphonylureas }\end{array}$ \\
\hline 6 & 34 & M & 1.4 & 41 & No & ?Hypoglycaemia due to alcohol or insulin \\
\hline 7 & 81 & $M$ & 0.6 & 234 & No & $\begin{array}{l}\text { Admitted with chronic obstructive airways disease. Reluctant } \\
\text { to be discharged. Later developed hypoglycaemic episodes. } \\
\text { Normoglycaemic on fasting. Source of sulphonylureas } \\
\text { unknown }\end{array}$ \\
\hline 8 & 81 & $M$ & 0.7 & 111 & No & $\begin{array}{l}\text { Collapsed at home, admitted via casualty. Discharged after } \\
\text { normoglycaemic on fasting. Source of sulphonylureas } \\
\text { unknown }\end{array}$ \\
\hline 9 & 25 & $\mathrm{~F}$ & 1.0 & 1850 & No & $\begin{array}{l}\text { Nurse living with another nurse. History of warfarin overdose } \\
\text { and epilepsy. Awaiting prolonged fast for investigation of } \\
\text { insulinoma. Munchausen syndrome }\end{array}$ \\
\hline 10 & 28 & $M$ & 2.7 & 2420 & No & $\begin{array}{l}\text { Attended several hospitals with hypoglycaemia. History of } \\
\text { pacemaker, partial pancreatectomy and investigation for } \\
\text { insulinoma. Diabetic relative and friends. Munchausen } \\
\text { syndrome }\end{array}$ \\
\hline
\end{tabular}

sulphonylureas are usually prescribed in much higher doses than glibenclamide and cases in which most of these drugs were proved subsequently to have been ingested (for the treatment of diabetes) have produced reference data against which positive results from factitious cases may be compared and their reliability assured.

The data from sulphonylurea-positive cases emphasize the importance of the screening aspect of the assay rather than the quantitative measurement. The absolute verification of drug concentration and identity requires chromatographic methods that are beyond the scope of the present study.

The frequency of positive cases, as a proportion of those referred for biochemical investigation, is based on the analytical outcome. The actual clinical incidence of hypoglycaemia induced by sulphonylureas may therefore be underestimated. Various audits of hospital admissions ${ }^{3,11}$ have reported that up to $6 \%$ of diabetic patients may be admitted with severe hypoglycaemia, as many as one-third are being treated with sulphonylureas, a finding remarkably similar to that in the present survey.

Of the 19 patients who were sulphonylurea-positive despite not having diabetes, 7 were older than 80 years, in agreement with the findings of other workers ${ }^{12,13}$. This is a group in which impaired cardiac, hepatic or renal function may increase sensitivity to these drugs ${ }^{14,15}$. In general, however, the patients were young, as noted elsewhere ${ }^{16}$, some with a history of working in healthcare or having relatives taking sulphonylureas for diabetes. Ingestion of sulphonylureas through dispensing errors has been well documented, often the result of poor handwriting on prescriptions ${ }^{12,16-19}$, and some of the patients in this study may come into this category. Accidental ingestion of sulphonylureas has also been described ${ }^{12}$ — perhaps because of confusion when a member of family or a friend is diabetic $^{20,21}$, or the unsuspecting use of a sulphonylurea as an adjunct to Chinese herbal therapy for fatigue ${ }^{16}$.

The details received on the cases involving mentally ill patients were generally insufficient to indicate whether sulphonylurea-induced hypoglycaemia had resulted from inadvertent ingestion, dispensing error, or deliberate administration by self or another. A common feature of psychiatric patients who abuse sulphonylureas is their willingness to undergo invasive procedures, including laparotomy $y^{5,16}$ and even resection of the pancreas ${ }^{20}$.

The proinsulin data are at variance with previous work by $\mathrm{Marks}^{22}$, who reported that proinsulin concentrations were higher in insulinomas than in sulphonylurea-induced hypoglycaemia. A proinsulin concentration of greater than $20 \mathrm{pmol} / \mathrm{L}$ was recommended as strong presumptive evidence of insulinoma ${ }^{4}$. Fajans and Vinik $^{23}$ found proinsulin greater than $22 \%$ of total immunoreactive insulin in 
$80-90 \%$ of patients with hyperinsulinism and considered proinsulin below $22 \%$ of total immunoreactive insulin as normal $^{23}$. We have found proinsulin concentrations of greater than $20 \mathrm{pmol} / \mathrm{L}$ and more than $22 \%$ of total immunoreactive insulin poor discriminators. For these reasons routine screening for sulphonylureas in all samples with inappropriately raised plasma insulin and C-peptide concentrations has become an essential part of the investigation of spontaneous hypoglycaemia.

Acknowledgments We thank Dr S Hampton for providing anti-glibenclamide serum, the pharmaceutical companies who supplied sulphonylureas, and many clinicians and colleagues throughout UK for referring specimens and submitting useful details. We are especially grateful to Professor V Marks for his help and guidance throughout these studies.

\section{REFERENCES}

1 Ferner RE, Neil HA. Sulphonylureas and hypoglycaemia. BMJ 1988; 296:949-50

2 Dahlen M, Bergman U, Idman L, Matinsson L, Karlsson G. Epidemiology of hypoglycaemia in patients on oral antidiabetic drugs in the Island of Gotland Sweden. Acta Endocrinol 1984;263(suppl.): abstract 21

3 Gill GV, Huddle KR. Hypoglycaemic admissions among diabetic patients in Soweto, South Africa. Diab Med 1993;10:181-3

4 Marks V, Teale JD. Investigation of hypoglycaemia. Clin Endocrinol 1996;44:133-6

5 Perros P, Henderson AK, Cater DC, Toft AD. Are spontaneous hypoglycaemia, raised plasma insulin and C-peptide concentrations, and abnormal pancreatic images enough to diagnose insulinoma? BMJ 1997; 314:496-7

6 Anonymous. Insulinoma. BMJ 1981;282:927-8

7 Service FJ, McMahon MM, O'Brien PC, Ballard DJ. Functioning insulinoma - incidence, recurrence, and long-term survival of patients: a 60-year study. Mayo Clin Proc 1991;66:711-19
8 Teale JD, Starkey BJ, Marks V, Hampton SM, Fisher RA, Levine DF. The prevalence of factitious hypoglycaemia due to sulphonylurea abuse in the UK: a preliminary report. Prac Diab 1989;6:177-8

9 Hampton SM, Withey L. Monitoring beta cell responses in obese and normal weight subjects - a pilot study. Diab Metabolisme 1993;19: $582-5$

10 Hampton SM, Beyzavi K, Teale JD, Marks V. A direct assay for proinsulin in plasma and its applications in hypoglycaemia. Clin Endocrinol 1988;29:9-16

11 Potter J, Clarke P, Gale EAM, Dave SH, Tattersall R. Insulin-induced hypoglycaemia in an accident and emergency department: the tip of an iceberg. BMJ 1982;285:1180-2

12 Seltzer HS. Drug-induced hypoglycaemia: a review of 1418 cases. Endocrinol Metab Clin N Am 1989;18:163-83

13 Asplund K, Wiholm B-E, Lithner F. Glibenclamide-associated hypoglycaemia: a report on 57 cases. Diabetologia 1983;24: 412-17

14 Sonnenblick M, Shilo S. Glibenclamide induced prolonged hypoglycaemia. Age Ageing 1986;15:185-9

15 Kennedy TD, Keat AC, Chester M, Oakley NW, Eastwood JB. Predisposing factors in fatal glibenclamide induced hypoglycaemia. Practical Diab 1988;5:217-19

16 Klonoff DC, Barrett BJ, Nolte MS, Cohen RM, Wyderski R. Hypoglycaemia following inadvertent and factitious sulphonylurea overdosages. Diab Care 1995; 18:563-7

17 Crowson TW, Kriel RL. Hypoglycaemia from the inadvertent use of oral hypoglycaemic agents. Ann Intern Med 1980;93:281-2

18 Labib M, Marks V. Inadvertent intake of sulphonylurea. Ann Clin Biochem 1990;27:382-3

19 Shumak SL, Corenblum B, Steiner G. Recurrent hypoglycaemia secondary to drug-dispensing error. Arch Intern Med 1991;151:1877-8

20 Jordan RM, Kammer H, Riddle MR. Sulphonylurea-induced factitious hypoglycaemia. A growing problem. Arch Intern Med 1977;137: 390-3

21 Sener A, Gillet C, Verhelst J, DeBoeck K, Mahler C, Malaisse WJ. Factitious hypoglycaemia documented by a modified assay for the measurement of plasma sulphonylurea. Diab Med 1995;12:433-5

22 Marks V. Hypoglycaemia - real and unreal, lawful and unlawful: the 1994 Banting lecture. Diab Med 1995;12:850-64

23 Fajans SS, Vinik AL. Insulin-producing islet cell tumours. Endocrinol Metab Clin N Am 1989;18:45-74 